\title{
Endoscopic ultrasound staging in patients with gastro-oesophageal cancers: a systematic review of economic evidence
}

\author{
Seow Tien Yeo ${ }^{1 *} \mathbb{D}$, Nathan Bray ${ }^{1}$, Hasan Haboubi ${ }^{2}$, Zoe Hoare ${ }^{3}$ and Rhiannon Tudor Edwards ${ }^{1}$
}

\begin{abstract}
Background: The sensitivity of endoscopic ultrasound (EUS) in staging gastro-oesophageal cancers (GOCS) has been widely studied. However, the economic evidence of EUS staging in the management of patients with GOCs is scarce. This review aimed to examine all economic evidence (not limited to randomised controlled trials) of the use of EUS staging in the management of GOCs patients, and to offer a review of economic evidence on the costs, benefits (in terms of GOCs patients' health-related quality of life), and economic implications of the use of EUS in staging GOCs patients.

Methods: The protocol was registered prospectively with PROSPERO (CRD42016043700; http://www.crd.york.ac.uk/ PROSPERO/display_record.php?ID=CRD42016043700). MEDLINE (ovid), EMBASE (ovid), The Cochrane Collaboration Register and Library (including the British National Health Service Economic Evaluation Database), CINAHL (EBSCOhost) and Web of Science (Core Collection) as well as reference lists were systematically searched for studies conducted between 1996 and 2018 (search update 28/04/2018). Two authors independently screened the identified articles, assessed study quality, and extracted data. Study characteristics of the included articles, including incremental cost-effectiveness ratios, when available, were summarised narratively.
\end{abstract}

Results: Of the 197 articles retrieved, six studies met the inclusion criteria: three economic studies and three economic modelling studies. Of the three economic studies, one was a cost-effectiveness analysis and two were cost analyses. Of the three economic modelling studies, one was a cost-effectiveness analysis and two were cost-minimisation analyses. Both of the cost-effectiveness analyses reported that use of EUS as an additional staging technique provided, on average, more QALYs (0.0019-0.1969 more QALYs) and saved costs (by £1969-£3364 per patient, 2017 price year) compared to staging strategy without EUS. Of the six studies, only one included GOCs participants and the other five included oesophageal cancer participants.

Conclusions: The data available suggest use of EUS as a complementary staging technique to other staging techniques for GOCs appears to be cost saving and offers greater QALYs. Nevertheless, future studies are necessary because the economic evidence around this EUS staging intervention for GOCs is far from robust. More health economic research and good quality data are needed to judge the economic benefits of EUS staging for GOCs.

PROSPERO Registration Number: CRD42016043700.

Keywords: Costs, Effects, QALYs, Economic review, Endoscopic ultrasound, EUS staging, Staging techniques, Gastro-oesophageal cancers

\footnotetext{
* Correspondence: s.t.yeo@bangor.ac.uk

${ }^{1}$ Centre for Health Economics and Medicines Evaluation (CHEME), Bangor

University, Ardudwy, Normal Site, Holyhead Road, Bangor, Gwynedd LL57

2PZ, UK

Full list of author information is available at the end of the article
}

(c) The Author(s). 2019 Open Access This article is distributed under the terms of the Creative Commons Attribution 4.0 International License (http://creativecommons.org/licenses/by/4.0/), which permits unrestricted use, distribution, and reproduction in any medium, provided you give appropriate credit to the original author(s) and the source, provide a link to the Creative Commons license, and indicate if changes were made. The Creative Commons Public Domain Dedication waiver (http://creativecommons.org/publicdomain/zero/1.0/) applies to the data made available in this article, unless otherwise stated. 


\section{Background}

Gastro-oesophageal (oesophageal or gastric, or both) cancers (GOCs) are one of the most common cancers in the UK with approximately 16,000 people diagnosed in 2015 [1, 2]. Oesophageal and gastric cancers were the seventh and fourteenth most common cause of cancer death respectively in the UK in 2016, as shown from the latest available statistics reported by the Cancer Research United Kingdom (CRUK) $[1,2]$. It is estimated that a total of around 12,500 people died from these cancers in 2016 - that is 34 deaths per day $[1,2]$. Accurate staging of GOCs is vital for determining prognosis and planning appropriate treatment. Accurate staging in the management of GOCs will not only help avoid unnecessary surgical interventions but also will ultimately help reduce the financial pressure on the NHS, which is particularly important given the limited resources available to cancer services and the growing incidence of GOCs [3].

Accurate staging of GOCs can be achieved by a combination of investigative techniques. The techniques used for staging GOC include computer tomography (CT), endoscopic ultrasound (EUS), positron emission tomography (PET) and adjuncts to staging include magnetic resonance imaging (MRI), bronchoscopy, laparoscopy and trans-abdominal ultrasound [4]. CT has been recommended for use at initial staging assessment to determine whether the cancer cells have spread from the primary site of its origin into new areas of the body (i.e. metastasis); but in the absence of metastatic disease, EUS has been advocated as the preferred technique for the assessment and prediction of operability [4]. This is due to the fact that EUS is superior to CT for local regional staging of oesophageal and gastric tumours [4].

Studies and guidelines for the management of oesophageal and gastric cancer have reported that EUS has superior tumour invasion $(\mathrm{T})$ and loco-regional nodal $(\mathrm{N})$ staging ability over CT and PET given its sensitivity, particularly for detection of regional lymph node metastases, although the complementary nature of these investigative techniques must be recognised [5-10]. The sensitivity of EUS for staging of GOC has been widely evaluated; however, the economic evidence of EUS staging in the management of GOC patients is scarce. Furthermore, the effectiveness and cost-effectiveness of EUS staging of GOC had not been assessed, particularly in the form of randomised controlled trials (RCT), until the establishment of "COGNATE" trial - a HTA-funded RCT UK study [11].

Given that the economic evidence of EUS for staging of GOC is scant, conducting a systematic review of the economic evidence on EUS staging in patients with GOC is therefore important. It not only gives a meaningful evidencebased insight, from an economic perspective, for researchers and clinical experts in this field but also healthcare commissioners. In view of that, this systematic review aimed to examine all economic evidence (not just from RCTs) of the use of EUS staging in the management of patients with GOC. Systematic reviews of economic evaluations review studies that evaluated both the effectiveness in terms of health effects (usually measured as life-years gained (LYGs) or quality-adjusted-life-years (QALYs), accounting for the quality-of-life outcomes) and cost of the alternative interventions assessed. Economic evaluation is performed by undertaking either a cost-effectiveness analysis (CEA), cost-utility analysis (CUA), cost-consequences analysis (CCA), costbenefit analysis (CBA) or cost-minimisation analysis (CMA). When clinical outcome expressed in natural units (e.g. LYGs, lives saved, improvement in pain score etc) are used as health effects in an economic analysis, this is often referred to as CEA with its parameter of interest being called incremental cost-effectiveness ratio (ICER). Whereas, when QALY, a common unit, is used as health effect in an economic analysis, then this is often referred to as CUA though CEA is preferred by some authors and the resulting parameter of interest is called incremental cost-utility ratio (ICUR). The ICER/ICUR is then compared with the official or approximate willingness to pay (WTP) ceiling ratio for a unit of effect, that is, threshold used for decision making. CCA reports costs and outcomes in disaggregated form for each alternative [12]. CBA converts clinical outcomes into monetary units so that a net benefit (or cost) can be estimated [12]. CMA measures which alternative has the least cost, this method is only applied when the outcomes of alternative interventions have been proven to be equivalent. The protocol of this systematic review was registered prospectively with PROSPERO, an international prospective register of systematic reviews (Registration number 2016:CRD42016043700; http://www.crd.york.ac.uk/PROSPERO/display_record. php?ID=CRD42016043700) [13]. This paper offers a review of economic evidence on the costs, benefits (in terms of GOC patients' health-related quality of life), and economic implications of the use of EUS for staging GOC patients.

\section{Methods}

This review was carried out and reported in accordance with the published updated Preferred Reporting Items for Systematic Reviews and Meta-Analyses (PRISMA) guidelines $[14,15]$.

\section{Searches and study selection}

Searches for this systematic review were conducted using a range of electronic databases: MEDLINE (ovid), EMBASE (ovid), The Cochrane Collaboration Register and Library (including Cochrane Central Register of Controlled Trials (CCRCT), Cochrane Reviews, Database of Abstracts of Reviews of Effects (DARE), Health Technology Assessment (HTA), British National Health Service Economic Evaluation Database (NHS EED), Cochrane Methodology Register (CMR)), CINAHL (EBSCOhost), Web of Science (Core 
Collection). Searches were restricted to publications from the last 20 years (1996-2016) as per the registered protocol on PROSPERO (Registration number 2016:CRD42016043700) [13]. To ensure that the review was as up-to-date as possible, the searches were re-run on all databases to cover 20162018 (search update on 28/04/2018).

In order to ensure a comprehensive search was achieved and any relevant research had not been missed, online searches were also conducted through the following internet search engines and appropriate websites to identify grey literature, reports, ongoing and unpublished studies from conference papers and abstracts: Google, Google Scholar, Department of Health (DoH), National Institute for Health and Clinical Excellence (NICE), National Institute for Health Research (NIHR) Journals Library, NIHR UK Clinical Trials Gateway, The National Cancer Research Institute (NCRI), Cancer Research Wales (CRW), Wales Cancer Research Centre (WCRC), Welsh Government (WG), Health and Care Research Wales (HCRW), CRUK and other relevant charitable organisation websites.

The reference lists of papers that were included in the review were searched for further publications that had not been identified in the electronic searches. Contacts with study authors were made to locate further relevant literature and publications.

Guided by the review objectives, the search terms as shown in Table 1 were developed using the PICO framework $[16,17]$. The PICO framework was utilised to help shape, design and construct the search process to identify all relevant published and unpublished materials from various sources. Titles, abstracts and full-text papers were searched for using these search terms.

The search strategy for each of the five electronic databases was developed, checked and tested by an information specialist before finalising the search terms; this process was informed by the search strategy of a wider evidence synthesis that includes a systematic review of non-economic studies of treatments for resectable adenocarcinoma of the stomach, gastro-oesophageal junction and lower oesophagus [18]. An example of search strategy used in the Medline Ovid database is as shown in the additional file (see Additional file 1).

\section{Inclusion and exclusion criteria}

Table 2 presents the inclusion and exclusion criteria, using the economic evidence review design framework outlined in the University of York Centre for Reviews and Dissemination (2009) [12]: Population, Interventions, Comparators, Outcomes, and Type of Evidence. Due to resources constraints, only studies written in English were included. This includes international studies that have been translated or written in English.

\section{Data extraction}

Titles and abstracts of all studies identified were screened and assessed for relevance against the inclusion criteria by two independent reviewers (STY and NB). The inclusion or exclusion of each study was checked and confirmed. All potentially relevant full-text papers were then obtained and screened against the inclusion criteria, with disagreements resolved through discussion until agreements were achieved collectively. Disagreements occurred when for example the reviewers had different views on whether a retrieved paper should be included in the review.

Following screening, relevant information from all fulltext papers included in the review were extracted by the primary reviewer (STY) using an adapted standardised form [12], and checked by the second reviewer (NB). Two adapted standardised forms were developed and used for data extraction - one for economic studies and another for economic modelling studies.

\section{Quality assessment}

The quality of all full-text papers included in the review were assessed and rated independently by the two reviewers using the Critical Appraisal Skills Programme (CASP) economic evaluation checklist [19] tool for economic studies and the Philips et al's economic modelling checklist [20] tool for economic modelling studies. The papers were critically appraised to assess to what extent the content of these papers complied with the criteria of good practice in economic evaluation and if there was any obvious bias. Disagreements between the reviewers were resolved through discussion until agreements were achieved collectively. Disagreements occurred when for example the reviewers had different score on an included paper.

\section{Data synthesis}

All studies included in the review were summarised and compared across studies in a narrative form to answer the review objectives. The aims, methods, and results of the studies reviewed were synthesised narratively. This demonstrates the heterogeneity of the studies in terms of characteristics [12]. Due to the heterogeneity of the studies in terms of the study type and outcomes across the studies, meta-analysis was not appropriate [12]. Costs were converted into British pounds sterling, $£$, using the appropriate exchange rate published in the International Monetary Fund [21] and inflated to 2017 price year using the hospital and community health services (HCHS) index [22-25] for the studies included in the review.

\section{Results}

Literature search: identification of studies

Overall, the search from 1996 to 2016 identified 197 potentially relevant studies, six of which fulfilled the 
Table 1 Search terms by category, guided by PICO framework, for the systematic review

\begin{tabular}{|c|c|c|}
\hline No. & Search Term Category & Search Terms \\
\hline \multirow[t]{9}{*}{1.} & Disease & neoplas* OR \\
\hline & & cancer* OR \\
\hline & & carcin* OR \\
\hline & & tumo* OR \\
\hline & & adenocarcinoma* OR \\
\hline & & squamous cell carcinoma* OR \\
\hline & & malig* OR \\
\hline & & metasta* \\
\hline & & AND \\
\hline \multirow[t]{30}{*}{2.} & Type of disease & gastro* OR \\
\hline & & oesophag* OR \\
\hline & & esophag* OR \\
\hline & & gastro-oesophag* OR \\
\hline & & gastro-esophag* OR \\
\hline & & gastroesophag* junction* OR \\
\hline & & gastro-esophag* junction* OR \\
\hline & & gastrooesophag* junction* OR \\
\hline & & gastro-oesophag* junction* OR \\
\hline & & esophagogastric junction* OR \\
\hline & & esophago-gastric junction* OR \\
\hline & & oesophagogastric junction* OR \\
\hline & & oesophago-gastric junction* OR \\
\hline & & oesophageal squamous cell carcinoma* OR \\
\hline & & esophageal squamous cell carcinoma* OR \\
\hline & & gut* OR \\
\hline & & gullet* OR \\
\hline & & food pipe OR \\
\hline & & stomach OR \\
\hline & & upper GI OR \\
\hline & & upper-GI OR \\
\hline & & upper gastrointestin* OR \\
\hline & & upper-gastrointestin* OR \\
\hline & & upper digestive tract* OR \\
\hline & & upper-digestive tract* $\mathrm{OR}$ \\
\hline & & intraepithelial OR \\
\hline & & intramucosal OR \\
\hline & & node* OR \\
\hline & & nodal \\
\hline & & AND \\
\hline \multirow[t]{5}{*}{3.} & Intervention & endosono* OR \\
\hline & & EUS OR \\
\hline & & endoscopic ultraso* OR \\
\hline & & endoscopic-ultraso* OR \\
\hline & & EUS-FNA OR \\
\hline
\end{tabular}


Table 1 Search terms by category, guided by PICO framework, for the systematic review (Continued)

\begin{tabular}{|c|c|c|}
\hline No. & Search Term Category & Search Terms \\
\hline & & EUS-fine needle aspiration OR \\
\hline & & EUS fine-needle aspiration OR \\
\hline & & Endosonography-guided FNA OR \\
\hline & & $\begin{array}{l}\text { Endoscopic ultrasound-fine needle } \\
\text { aspiration OR }\end{array}$ \\
\hline & & $\begin{array}{l}\text { Endoscopic ultrasound-guided fine needle } \\
\text { aspiration OR }\end{array}$ \\
\hline & & $\begin{array}{l}\text { Endoscopic ultrasound-guided fine-needle } \\
\text { aspiration OR }\end{array}$ \\
\hline & & $\begin{array}{l}\text { Endoscopic-ultrasound-guided fine-needle } \\
\text { aspiration OR }\end{array}$ \\
\hline & & $\begin{array}{l}\text { Endoscopic ultrasound guided fine needle } \\
\text { aspiration OR }\end{array}$ \\
\hline & & Echoendoscop* OR \\
\hline & & Echo-endoscop* \\
\hline & & AND \\
\hline & & Staging OR \\
\hline & & Preoperative staging OR \\
\hline & & Pre-operative staging \\
\hline & & AND \\
\hline \multirow[t]{26}{*}{4.} & Outcome & econom* OR \\
\hline & & health economics OR \\
\hline & & economic evaluation OR \\
\hline & & cost-effective* OR \\
\hline & & cost effect* OR \\
\hline & & cost utility OR \\
\hline & & cost-utility OR \\
\hline & & cost-conseq* OR \\
\hline & & cost conseq* OR \\
\hline & & cost-benefit OR \\
\hline & & cost benefit OR \\
\hline & & cost-minimisation OR \\
\hline & & cost minimisation $\mathrm{OR}$ \\
\hline & & cost-minimization OR \\
\hline & & cost minimization $\mathrm{OR}$ \\
\hline & & cost ${ }^{*}$ OR \\
\hline & & cost $^{*}$ analys $\mathrm{OR}$ \\
\hline & & unit cost OR \\
\hline & & unit-cost OR \\
\hline & & unit-costs OR \\
\hline & & unit costs $O R$ \\
\hline & & drug cost OR \\
\hline & & drug costs OR \\
\hline & & hospital costs OR \\
\hline & & health-care costs OR \\
\hline & & health care cost OR \\
\hline
\end{tabular}


Table 1 Search terms by category, guided by PICO framework, for the systematic review (Continued)

\begin{tabular}{|c|c|c|}
\hline No. & Search Term Category & Search Terms \\
\hline & & medical cost OR \\
\hline & & medical costs OR \\
\hline & & cost $^{*}$ efficacy* OR \\
\hline & & cost* $^{*}$ analys* OR \\
\hline & & 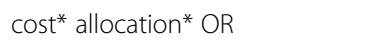 \\
\hline & & cost $^{*}$ control* $^{*} \mathrm{OR}$ \\
\hline & & cost* $^{*}$ illness ${ }^{*} \mathrm{OR}$ \\
\hline & & cost* $^{*}$ affordable* OR \\
\hline & & cost $^{*}$ fee $e^{*}$ OR \\
\hline & & cost $^{*}$ charge ${ }^{*}$ \\
\hline & & economic model* OR \\
\hline & & markov* OR \\
\hline & & budget* OR \\
\hline & & healthcare economics OR \\
\hline & & health care economics OR \\
\hline & & cost analys* OR \\
\hline & & health-care cost* OR \\
\hline & & health care cost* OR \\
\hline & & hrqol OR \\
\hline & & Health related quality of life $O R$ \\
\hline & & health-related quality of life OR \\
\hline & & quality-adjusted life year* OR \\
\hline & & quality adjusted life year* OR \\
\hline & & qaly $O R$ \\
\hline & & Quality of life OR \\
\hline & & quality-of-life $O R$ \\
\hline & & QoL \\
\hline
\end{tabular}

inclusion criteria and were included in the review (Fig. 1). Of the six studies included, three were economic analysis studies and three were economic modelling studies.

To ensure that the review was as up-to-date as possible, the searches were re-run on all databases to cover 2016-2018 (search update on 28/04/2018); 30 potentially relevant papers were identified but none met the inclusion criteria. In such case, the final number of studies included in the review remained at six.

\section{Study descriptions}

Tables 3 and 4 summarises the characteristics of the six studies included in the review. There were three economic analysis studies (Table 3) and three economic modelling studies (Table 4). Five of the studies included in the review were US studies, and one was a UK study. Of the three economic analysis studies, two were cost analyses [26, 27] and one was a cost-effectiveness analysis [11]. Of the three economic modelling studies, two were cost-minimisation analyses $[29,30]$ and one was a cost-effectiveness analysis [31]. All of the three economic modelling studies used decision tree modelling techniques to explore staging strategies.

The six studies included in the review differed quite markedly in terms of their design. Only one study used primary cost and outcome data collected in prospective evaluation [11], one study used data collected in prospective case series [27], one study used retrospective data [26], and the remaining three studies synthesised data from secondary sources in a decision tree model [29-31]. Of the six studies, only one [11] was a randomised controlled trial and included participants diagnosed with gastro-oesophageal cancer (i.e. oesophageal, gastro-oesophageal junction or gastric cancer); the other five were non-trial studies and included participants diagnosed with oesophageal cancer. Amongst the six studies, Russell et al. (2013) [11] was again the only study which evaluated costs of health care resource use 
Table 2 Inclusion and exclusion criteria for the systematic review

\begin{tabular}{|c|c|c|}
\hline & Inclusion Criteria & Exclusion Criteria \\
\hline Population & $\begin{array}{l}\text { All adults (aged } 19 \text { and above) who had cancer } \\
\text { (i.e. localised tumour) of the oesophagus, } \\
\text { stomach or gastro-oesophageal junction; free } \\
\text { of metastatic disease. }\end{array}$ & $\begin{array}{l}\text { Population aged below } 19 \text { years and had metastatic } \\
\text { oesophageal, gastro-oesophageal or gastric cancer. }\end{array}$ \\
\hline Interventions & $\begin{array}{l}\text { Use of endoscopic ultrasound (EUS) (also known } \\
\text { as endosonography, echoendoscopy) staging } \\
\text { in patient with oesophagus, gastro-oesophageal } \\
\text { and gastric cancer. }\end{array}$ & $\begin{array}{l}\text { Use of endoscopy only or ultrasound only, and use } \\
\text { of EUS for non-cancer staging purposes e.g. treatment } \\
\text { of cancer }\end{array}$ \\
\hline Comparators & $\begin{array}{l}\text { Standard staging algorithm e.g. trans-abdominal } \\
\text { ultrasound scan, computed tomography }(\mathrm{CT}) \text { scan. } \\
\text { Partial economic evaluations, when no formal } \\
\text { comparator was used, were included. }\end{array}$ & \\
\hline Outcomes & $\begin{array}{l}\text { All relevant full economic evaluation studies } \\
\text { outcomes including (but not be restricted to) } \\
\text { cost per QALY and cost per life-year gained; } \\
\text { All other relevant economic outcomes including } \\
\text { (but not be restricted to) resource use, direct and } \\
\text { indirect costs, incremental benefits e.g. quality-adjusted } \\
\text { survival or quality-adjusted life years (QALYs), } \\
\text { health-related quality of life, cancer-specific quality of life } \\
\text { and utility gained - this includes partial economic } \\
\text { evaluation studies outcomes, which costs or consequences } \\
\text { alone of a single intervention (e.g. EUS staging of GOC) } \\
\text { were described, were included. }\end{array}$ & $\begin{array}{l}\text { All outcomes unrelated to economic evidence of EUS } \\
\text { staging of the oesophagus, gastro-oesophageal junction } \\
\text { or gastric cancer. }\end{array}$ \\
\hline $\begin{array}{l}\text { Type of } \\
\text { Evidence }\end{array}$ & $\begin{array}{l}\text { Full economic evaluation evidence (i.e. cost-effectiveness, } \\
\text { cost-utility and cost-benefit analyses) related to EUS staging } \\
\text { of oesophageal, gastro-oesophageal junction and gastric } \\
\text { cancer were considered. } \\
\text { Other economic studies that contain partial economic } \\
\text { evaluation or no evaluation context (e.g. cost analyses, } \\
\text { cost-description studies, cost-outcome descriptions, } \\
\text { budgetary studies, outcome-description studies in terms } \\
\text { of utility gained, health-related quality of life and } \\
\text { cancer-specific quality of life measures such as QALYs } \\
\text { and FACT-G score) were also considered. } \\
\text { Economic evaluation studies conducted alongside RCTs, } \\
\text { non-RCTs, quasi-experimental trials, epidemiological research, } \\
\text { cohort studies, and modelling studies were considered. }\end{array}$ & $\begin{array}{l}\text { Non-research studies such as editorials, case reports or other } \\
\text { descriptive studies. }\end{array}$ \\
\hline General & $\begin{array}{l}\text { Language - English. } \\
\text { Years - 1996-2016 and 2016-2018 }\end{array}$ & $\begin{array}{l}\text { Language - Not written or translated into English. } \\
\text { Years - Before } 1996 .\end{array}$ \\
\hline
\end{tabular}

covering secondary care contacts and hospital prescribed drugs in addition to cost of EUS, collected prospectively in the trial.

In terms of health outcome measures, two studies $[11,31]$ included quality-adjusted life year (QALY) as the measure of effect and conducted a cost-effectiveness analysis to assess the gain in QALYs relative to the costs of different staging strategies. The remaining four studies $[26,27,29,30]$ did not explore QALY or other quality of life measures but only cost.

\section{Quality assessment}

Each of the six studies included in the review were critically appraised against the appropriate source of quality appraisal checklist: the CASP economic evaluation checklist [19] was used for the three economic studies, and Philips et al's economic modelling checklist [20] was used for the remaining three economic modelling studies. Table 5 and Table 6 summarised the quality assessment of the three economic studies and three economic modelling studies, respectively.

Table 5 shows the study quality of the three economic studies was generally good, scoring on average greater than $75 \%$, although only one study [11] met all quality criteria on the CASP economic evaluation checklist. The study by Shumaker et al. (2002) [26] scored the second highest, followed by Chang et al. (2003) [27]. Of these three economic studies, two had missing key information: Chang et al. (2003) [27] reported neither cost perspective, cost inflation, discounting nor price year, and sensitivity analysis was not undertaken; likewise, Shumaker et al. (2002) [26] did not state whether their reported costs were discounted or inflated as appropriate.

Table 6 shows the study quality of the three economic modelling studies included in the review was 


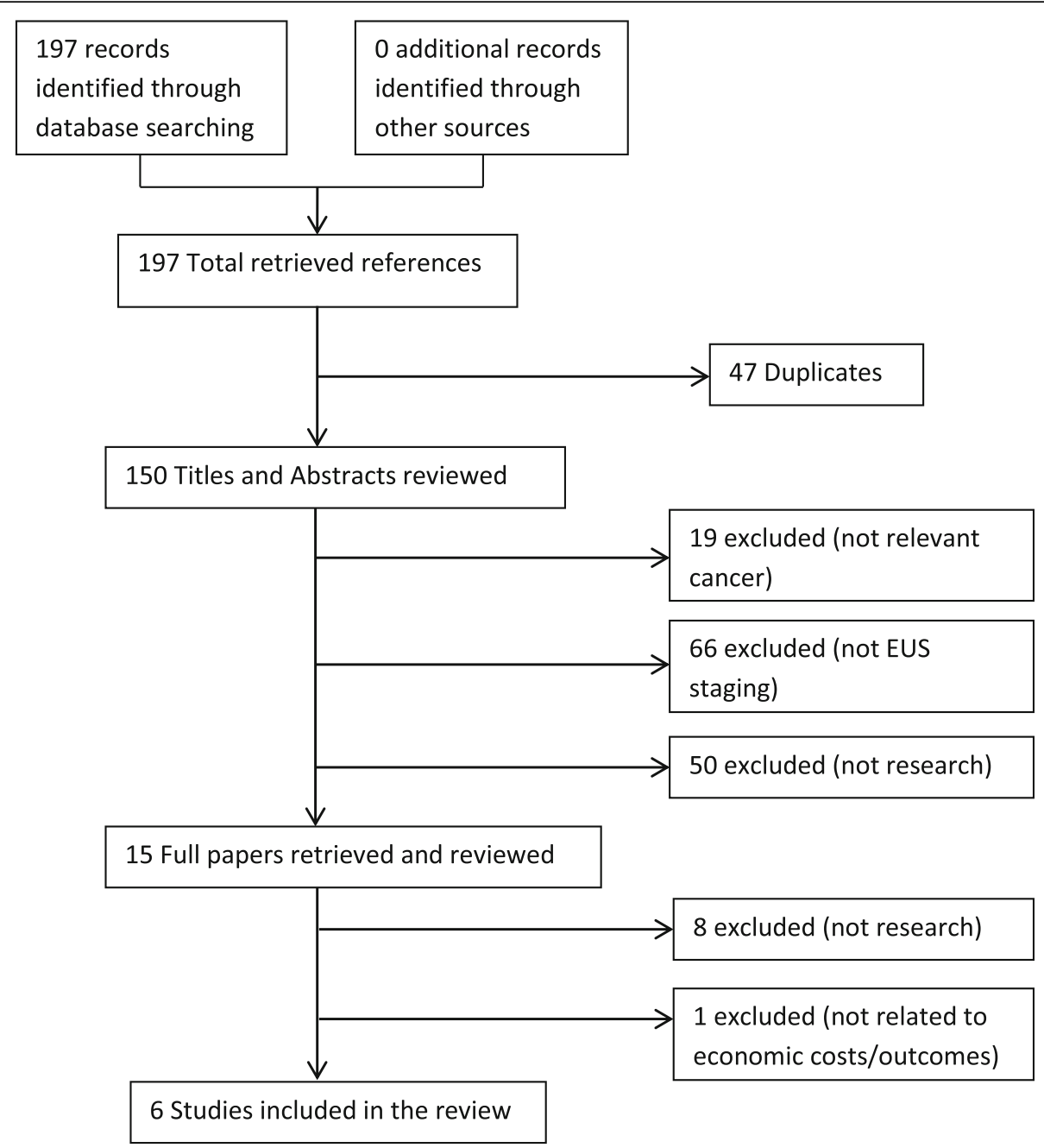

Fig. 1 Flowchart of the study selection process

satisfactory, scoring moderately well on the Philips et al's economic modelling checklist. In descending order of quality, the study by Wallace et al. (2002) [31] scored the highest followed by Harewood et al. (2002) [30] and Hadzijahic et al. (2000) [29]. One study [29] did not state the perspective of the model and all three [29-31] did not specify the time horizon of the decision tree model. There was insufficient detail of how parameters in the model were identified [31] and how data were modelled [30]. There was also a lack of clarity with regards to the source of probabilities and cost data used in the decision tree model [29].

\section{Data synthesis results}

All of the six studies included in the review exhibit EUS as a complementary imaging technique to other imaging modalities such as CT and PET scanning for staging gastro-oesophageal cancer. This is in agreement with a previously published meta-analysis study of diagnostic test characteristics for EUS, CT, and PET scanning [8], concluding that the three approaches were complementary.

Results from three of the economic studies [11, 26, 27] show staging of oesophageal or gastro-oesophageal cancer with EUS could potentially save costs. Similarly, results from two of the modelling studies $[29,30]$ show that EUS or EUS-fine-needle aspiration biopsy (FNA) is the least costly staging technique for oesophageal cancer. The study by Wallace et al. (2002) [31] shows that EUS-FNA in addition to CT scan is the least costly strategy than all other strategies i.e. CT alone, CT+ thoracoscopy and laparoscopy (TL), $\mathrm{CT}+\mathrm{EUS}-\mathrm{FNA}+\mathrm{TL}, \mathrm{CT}+\mathrm{PET}+\mathrm{EUS}-\mathrm{FNA}$ and PET+EUSFNA.

Results from the two studies $[11,31]$ in which qualityadjusted life year (QALY) and cost data were available demonstrate the use of EUS [11] or EUS-FNA [31] as an additional staging technique for gastro-oesophageal cancer offered more QALYs and costed less, on average, compared to staging techniques without EUS. Russell et 


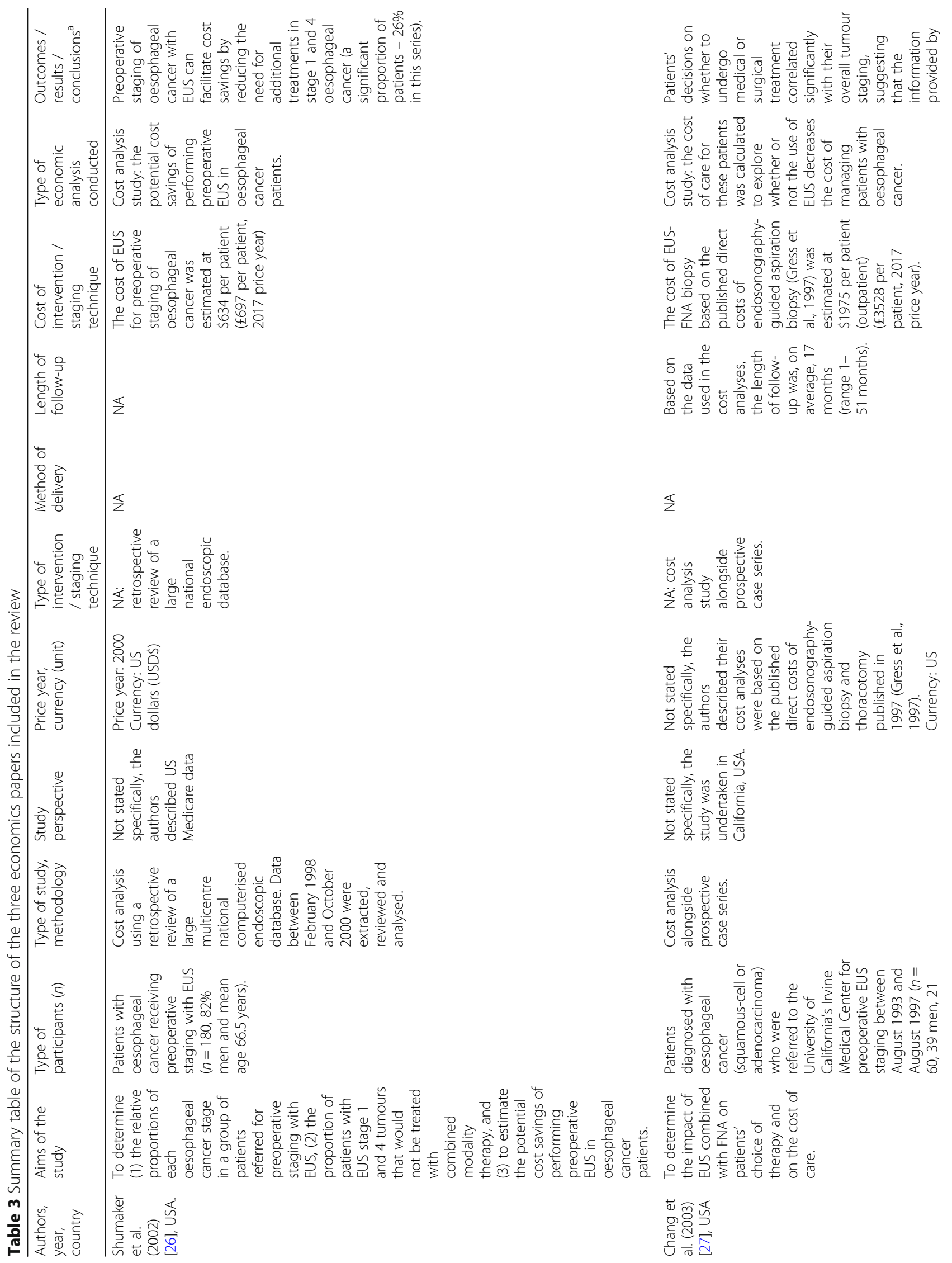




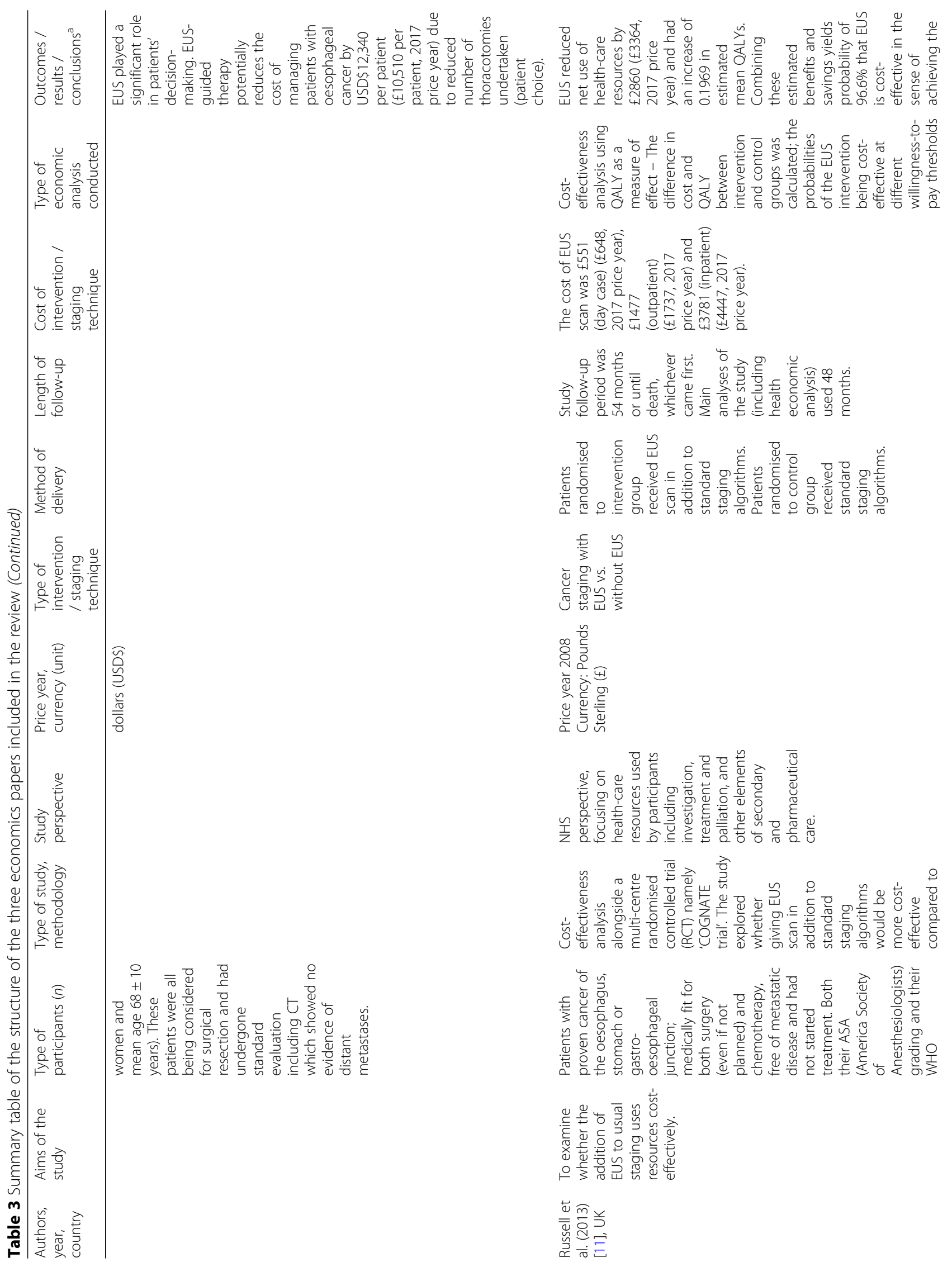


Yeo et al. BMC Cancer (2019) 19:900

Page 11 of 19

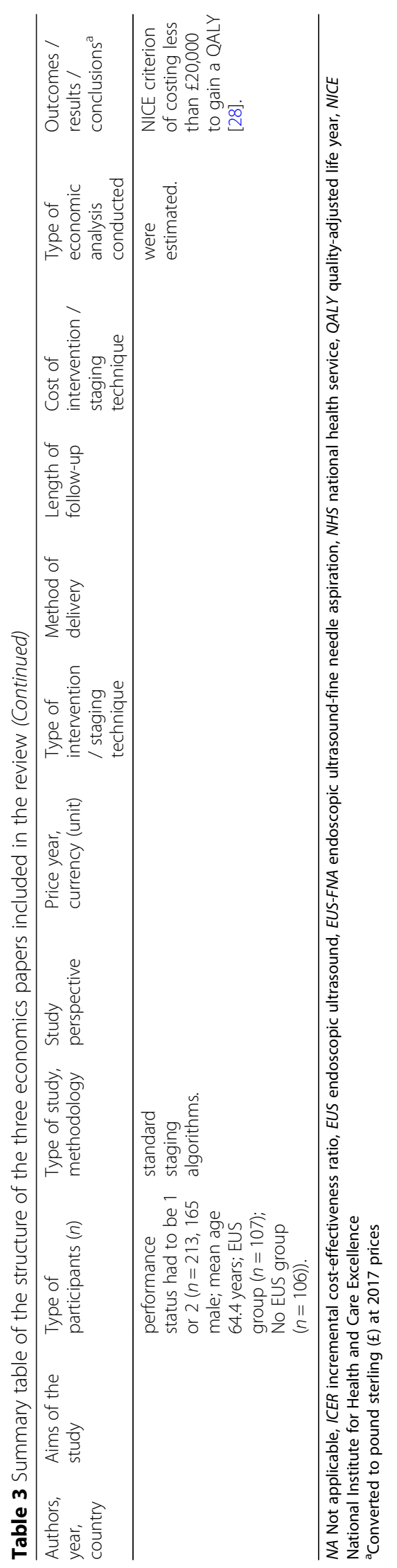




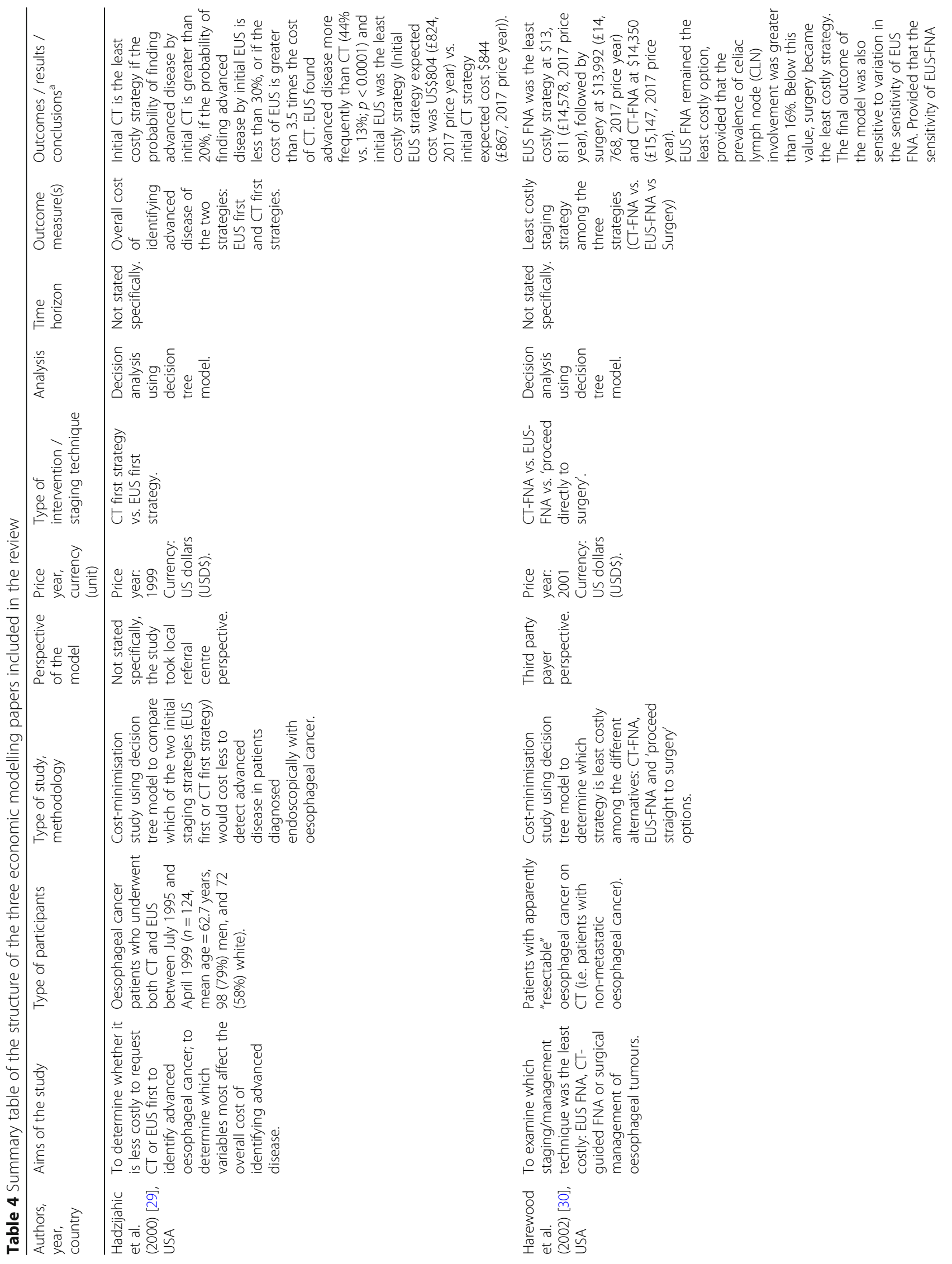




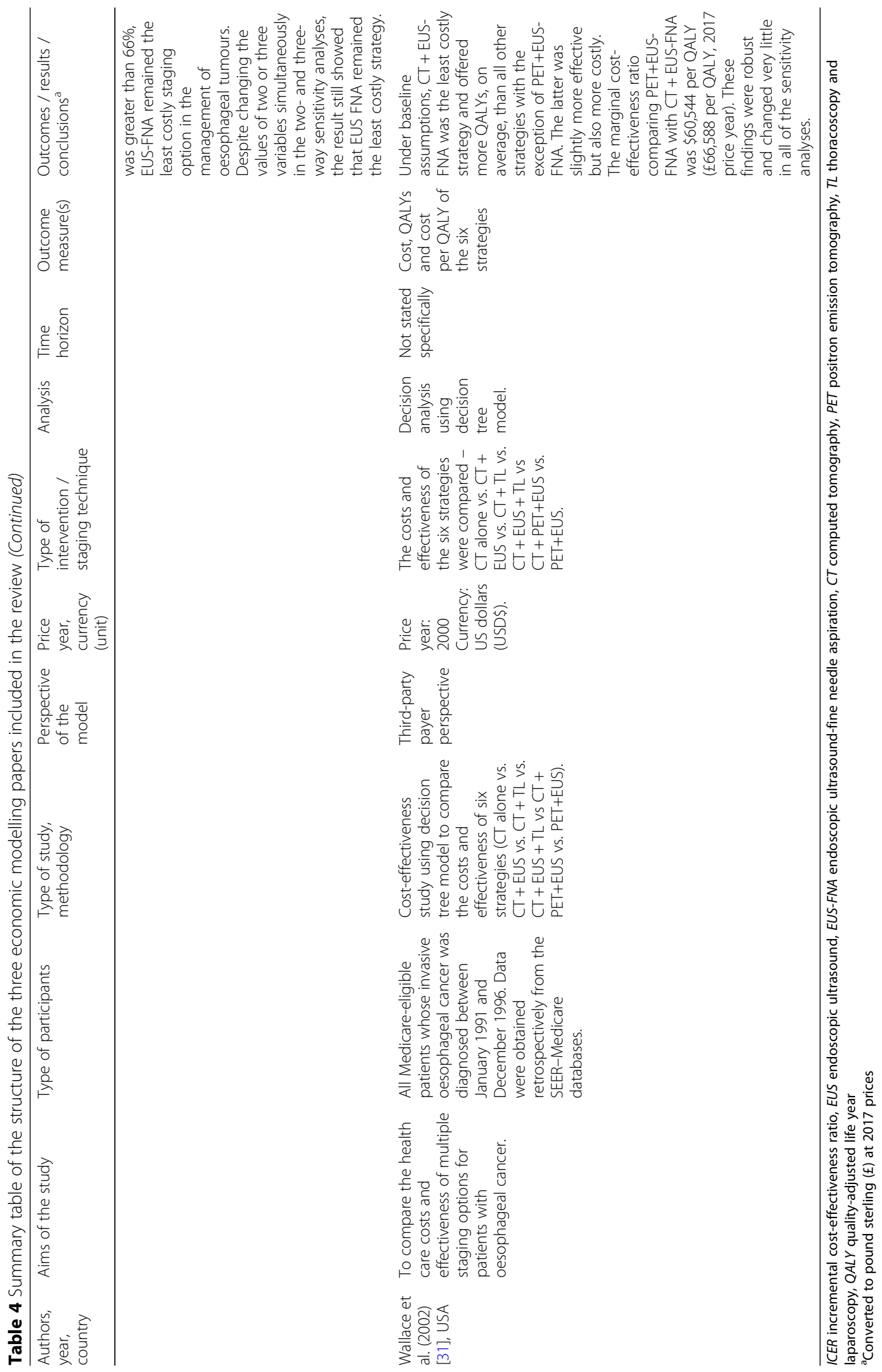


Table 5 Quality assessment results of economic studies included in the systematic review

\begin{tabular}{|c|c|c|c|c|}
\hline \multirow[t]{3}{*}{$\begin{array}{l}\text { Question } \\
\text { no. }\end{array}$} & \multirow[t]{3}{*}{ CASP economic evaluation checklist questions ${ }^{\mathrm{ab}}$} & \multicolumn{3}{|l|}{$\begin{array}{l}\text { Response } \\
(\sqrt{ }, x, N C \text { or NA) }\end{array}$} \\
\hline & & \multicolumn{3}{|c|}{ Studies (author and year) } \\
\hline & & $\begin{array}{l}\text { Shumaker et al. } \\
\text { (2002) [26] }\end{array}$ & $\begin{array}{l}\text { Chang et al. } \\
\text { (2003) [27] }\end{array}$ & $\begin{array}{l}\text { Russell et al. } \\
\text { (2013) [11] }\end{array}$ \\
\hline 1 & Was a well-defined question posed? & $\sqrt{ }$ & $\sqrt{ }$ & $\sqrt{ }$ \\
\hline 2 & $\begin{array}{l}\text { Was a comprehensive description of the competing } \\
\text { alternatives given? }\end{array}$ & NA & NA & $\sqrt{ }$ \\
\hline 3 & $\begin{array}{l}\text { Does the paper provide evidence that the programme } \\
\text { would be effective (i.e. would the programme do more } \\
\text { good than harm)? }\end{array}$ & $\sqrt{ }$ & $\sqrt{ }$ & $\sqrt{ }$ \\
\hline 4 & $\begin{array}{l}\text { Were the effects of the intervention identified, measured } \\
\text { and valued appropriately? }\end{array}$ & NA & NA & $\sqrt{ }$ \\
\hline $5 a$ & $\begin{array}{l}\text { Were all important and relevant resources required and } \\
\text { health outcome costs for each alternative identified? }\end{array}$ & NC & NC & $\sqrt{ }$ \\
\hline $5 b$ & $\begin{array}{l}\text { Were all important and relevant resources required and } \\
\text { health outcome costs for each alternative measured in } \\
\text { appropriate units? }\end{array}$ & $\sqrt{ }$ & $\sqrt{ }$ & $\sqrt{ }$ \\
\hline $5 c$ & $\begin{array}{l}\text { Were all important and relevant resources required and } \\
\text { health outcome costs for each alternative valued credibly? }\end{array}$ & $\sqrt{ }$ & NC & $\sqrt{ }$ \\
\hline 6 & $\begin{array}{l}\text { Were costs and consequences adjusted for different } \\
\text { times at which they occurred (discounting)? }\end{array}$ & $x$ & $x$ & $\sqrt{ }$ \\
\hline 7 & What were the results of the evaluation? & $\sqrt{ }$ & $\sqrt{ }$ & $\sqrt{ }$ \\
\hline 8 & $\begin{array}{l}\text { Was an incremental analysis of the consequences and } \\
\text { cost of alternatives performed? }\end{array}$ & NA & NA & $\sqrt{ }$ \\
\hline 9 & Was an adequate sensitivity analysis performed? & $\sqrt{ }$ & $x$ & $\sqrt{ }$ \\
\hline 10 & $\begin{array}{l}\text { Is the programme likely to be equally effective in your } \\
\text { context or setting? }\end{array}$ & $\sqrt{ }$ & $\sqrt{ }$ & $\sqrt{ }$ \\
\hline 11 & Are the costs translatable to your setting? & $x$ & $x$ & $\sqrt{ }$ \\
\hline 12 & Is it worth doing in your setting? & $\sqrt{ }$ & $\sqrt{ }$ & $\sqrt{ }$ \\
\hline Score, ratio ${ }^{\mathrm{TM}}(\%)$ & & $8 / 11(73 \%)$ & $6 / 11(55 \%)$ & $14 / 14(100 \%)$ \\
\hline
\end{tabular}

NA Not Applicable, NC Not Clear

a[19] Available from: http://www.casp-uk.net/casp-tools-checklists

${ }^{b}$ Adapted from: Drummond MF, Stoddart GL, Torrance GW. Methods for the economic evaluation of health care programmes. Oxford: Oxford University Press, 1987

${ }^{\text {TmRatio }}=\mathrm{b} / \mathrm{a}$, where $\mathrm{b}=$ sum of tick; $\mathrm{a}=$ sum of items (excluding 'NA' items)

al. (2013) [11] reported that EUS resulted in a QALY gain of 0.1969 QALYs and saved costs by $£ 2860$, on average, per patient ( $₫ 3364$ per patient, 2017 price year); combining these benefits and savings demonstrates that EUS is likely to be cost-effective with a probability of $96 \%$ at the UK NICE's threshold of $£ 20,000-£ 30,000$ per QALY [28].

Similarly, Wallace et al. (2002)'s [31] modelling study showed that using EUS-FNA as an additional staging technique offered greater QALYs and saved more costs, on average, than staging strategy without EUS. For example, the combination of CT and EUS-FNA (CT + EUS-FNA) provided 0.0019 more QALYs and saved US\$1790, on average, per patient ( $£ 1969$ per patient, 2017 price year) compared to CT alone strategy. The authors argued that, among all the six staging strategies evaluated (i.e. CT alone, CT + EUSFNA, CT + TL, CT + EUS-FNA + TL, CT + PET+EUS-FNA and PET+EUS-FNA), CT + EUS-FNA was the least costly strategy (US\$40,363) (£44,392, 2017 price year) and offered higher QALYs on average (0.9649) than all other strategies with the exception of PET+EUS-FNA (US\$44,521 for 1.0336 QALYs) ( $£ 48,965,2017$ price year). The latter was slightly more effective (by 0.0687 QALYs on average) but more costly (by US $\$ 4158$ on average [ $€ 4573,2017$ price year]) compared with CT + EUS-FNA, yielding a marginal cost-effectiveness ratio of US\$60,544 per QALY ( $£ 66,588$ per QALY, 2017 price year), a ratio that is less than that of other medical treatments but above accepted thresholds in the USA and UK.

\section{Discussion}

\section{Main findings}

This systematic review of economic evidence of EUS staging in patients with GOC revealed a considerably small number of relevant studies. Studies varied in quality, study design and method. Study quality was generally satisfactory across 
Table 6 Quality assessment results of economic modelling studies included in the systematic review

\begin{tabular}{|c|c|c|c|c|}
\hline \multirow[t]{3}{*}{$\begin{array}{l}\text { Quality } \\
\text { Criterion }\end{array}$} & \multirow[t]{3}{*}{ Philips et al' economic modelling checklist questions ${ }^{a}$} & \multicolumn{3}{|l|}{$\begin{array}{l}\text { Response } \\
(\sqrt{ }, \mathrm{x}, \mathrm{NC} \text { or } \mathrm{NA})\end{array}$} \\
\hline & & \multicolumn{3}{|c|}{ Studies (author and year) } \\
\hline & & $\begin{array}{l}\text { Hadzijahic et al. } \\
\text { (2000) [29] }\end{array}$ & $\begin{array}{l}\text { Harewood et al. } \\
(2002)[30]\end{array}$ & $\begin{array}{l}\text { Wallace et al. } \\
\text { (2002) [31] }\end{array}$ \\
\hline \multirow[t]{3}{*}{ S1 } & Is there a clear statement of the decision problem? & $\sqrt{ }$ & $\sqrt{ }$ & $\sqrt{ }$ \\
\hline & $\begin{array}{l}\text { Is the objective of the evaluation and model specified } \\
\text { and consistent with the stated decision problem? }\end{array}$ & $\sqrt{ }$ & $\sqrt{ }$ & $\sqrt{ }$ \\
\hline & Is the primary decision-maker specified? & NC & $\sqrt{ }$ & $\sqrt{ }$ \\
\hline \multirow[t]{4}{*}{ S2 } & Is the perspective of the model stated clearly? & $x$ & $\sqrt{ }$ & $\sqrt{ }$ \\
\hline & $\begin{array}{l}\text { Are the model inputs consistent with the } \\
\text { stated perspective? }\end{array}$ & NC & $\sqrt{ }$ & $\sqrt{ }$ \\
\hline & $\begin{array}{l}\text { Has the scope of the model been stated } \\
\text { and justified? }\end{array}$ & $\sqrt{ }$ & $\sqrt{ }$ & $\sqrt{ }$ \\
\hline & $\begin{array}{l}\text { Are the outcomes of the model consistent with the } \\
\text { perspective, scope and overall objective of the model? }\end{array}$ & $\sqrt{ }$ & $\sqrt{ }$ & $\sqrt{ }$ \\
\hline \multirow[t]{3}{*}{ S3 } & $\begin{array}{l}\text { Is the structure of the model consistent with a coherent } \\
\text { theory of the health condition under evaluation? }\end{array}$ & $\sqrt{ }$ & $\sqrt{ }$ & $\sqrt{ }$ \\
\hline & $\begin{array}{l}\text { Are the sources of data used to develop the structure } \\
\text { of the model specified? }\end{array}$ & $\sqrt{ }$ & $\sqrt{ }$ & $\sqrt{ }$ \\
\hline & $\begin{array}{l}\text { Are the causal relationships described by the model } \\
\text { structure justified appropriately? }\end{array}$ & NA & NA & NA \\
\hline \multirow[t]{2}{*}{ S4 } & Are the structural assumptions transparent and justified? & $\sqrt{ }$ & $\sqrt{ }$ & $\sqrt{ }$ \\
\hline & $\begin{array}{l}\text { Are the structural assumptions reasonable given the overall } \\
\text { objective, perspective and scope of the model? }\end{array}$ & $\sqrt{ }$ & $\sqrt{ }$ & $\sqrt{ }$ \\
\hline \multirow[t]{3}{*}{ S5 } & Is there a clear definition of the options under evaluation? & $\sqrt{ }$ & $\sqrt{ }$ & $\sqrt{ }$ \\
\hline & Have all feasible and practical options been evaluated? & $\sqrt{ }$ & $\sqrt{ }$ & $\sqrt{ }$ \\
\hline & Is there justification for the exclusion of feasible options? & NA & NA & NA \\
\hline S6 & $\begin{array}{l}\text { Is the chosen model type appropriate given the decision } \\
\text { problem and specified causal relationships within the model? }\end{array}$ & $\sqrt{ }$ & $\sqrt{ }$ & $\sqrt{ }$ \\
\hline \multirow[t]{2}{*}{ S7 } & $\begin{array}{l}\text { Is the time horizon of the model sufficient to reflect all } \\
\text { important differences between options? }\end{array}$ & $x$ & $x$ & $x$ \\
\hline & $\begin{array}{l}\text { Are the time horizon of the model, the duration of treatment } \\
\text { and the duration of treatment effect described and justified? }\end{array}$ & $x$ & $x$ & $x$ \\
\hline$\$ 8$ & $\begin{array}{l}\text { Do the disease states (state transition model) or the } \\
\text { pathways (decision tree model) reflect the underlying } \\
\text { biological process of the disease in question and the } \\
\text { impact of interventions? }\end{array}$ & $\sqrt{ }$ & $\sqrt{ }$ & $\sqrt{ }$ \\
\hline 59 & $\begin{array}{l}\text { Is the cycle length defined and justified in terms of the } \\
\text { natural history of disease? }\end{array}$ & NA & NA & NA \\
\hline \multirow[t]{5}{*}{ D1 } & $\begin{array}{l}\text { Are the data identification methods transparent and } \\
\text { appropriate given the objectives of the model? }\end{array}$ & $\sqrt{ }$ & NC & $\sqrt{ }$ \\
\hline & $\begin{array}{l}\text { Where choices have been made between data sources, } \\
\text { are these justified appropriately? }\end{array}$ & NA & $\sqrt{ }$ & $\sqrt{ }$ \\
\hline & $\begin{array}{l}\text { Has particular attention been paid to identifying data } \\
\text { for the important parameters in the model? }\end{array}$ & $\sqrt{ }$ & $\sqrt{ }$ & $x$ \\
\hline & Has the quality of the data been assessed appropriately? & $x$ & $x$ & $x$ \\
\hline & $\begin{array}{l}\text { Where expert opinion has been used, are the methods } \\
\text { described and justified? }\end{array}$ & NA & NA & $x$ \\
\hline D2 & $\begin{array}{l}\text { Is the data modelling methodology based on justifiable } \\
\text { statistical and epidemiological techniques? }\end{array}$ & $\sqrt{ }$ & NC & $\sqrt{ }$ \\
\hline \multirow[t]{4}{*}{ D2a } & Is the choice of baseline data described and justified? & $\sqrt{ }$ & $\sqrt{ }$ & $\sqrt{ }$ \\
\hline & Are transition probabilities calculated appropriately? & NA & NA & NA \\
\hline & $\begin{array}{l}\text { Has a half-cycle correction been applied to both } \\
\text { cost and outcome? }\end{array}$ & NA & NA & NA \\
\hline & If not, has this omission been justified? & NA & NA & NA \\
\hline D2b & If relative treatment effects have been derived & NA & NA & NA \\
\hline
\end{tabular}


Table 6 Quality assessment results of economic modelling studies included in the systematic review (Continued)

\begin{tabular}{|c|c|c|c|c|}
\hline \multirow[t]{3}{*}{$\begin{array}{l}\text { Quality } \\
\text { Criterion }\end{array}$} & \multirow[t]{3}{*}{ Philips et al' economic modelling checklist questions ${ }^{a}$} & \multicolumn{3}{|l|}{$\begin{array}{l}\text { Response } \\
(\sqrt{ }, x, N C \text { or } N A)\end{array}$} \\
\hline & & \multicolumn{3}{|c|}{ Studies (author and year) } \\
\hline & & $\begin{array}{l}\text { Hadzijahic et al. } \\
\text { (2000) [29] }\end{array}$ & $\begin{array}{l}\text { Harewood et al. } \\
(2002)[30]\end{array}$ & $\begin{array}{l}\text { Wallace et al. } \\
\text { (2002) [31] }\end{array}$ \\
\hline & appropriate techniques? & & & \\
\hline & $\begin{array}{l}\text { Have the methods and assumptions used to extrapolate } \\
\text { short-term results to final outcomes been documented } \\
\text { and justified? }\end{array}$ & NA & NA & NA \\
\hline & $\begin{array}{l}\text { Have alternative assumptions been explored through } \\
\text { sensitivity analysis? }\end{array}$ & $\sqrt{ }$ & $\sqrt{ }$ & $\sqrt{ }$ \\
\hline & $\begin{array}{l}\text { Have assumptions regarding the continuing effect of } \\
\text { treatment once treatment is complete been documented } \\
\text { and justified? }\end{array}$ & NA & NA & NA \\
\hline & $\begin{array}{l}\text { Have alternative assumptions regarding the continuing } \\
\text { effect of treatment been explored through sensitivity analysis? }\end{array}$ & NA & NA & NA \\
\hline \multirow[t]{3}{*}{ D2c } & Are the costs incorporated into the model justified? & $\sqrt{ }$ & $\sqrt{ }$ & $\sqrt{ }$ \\
\hline & Has the source for all costs been described? & $\sqrt{ }$ & $\sqrt{ }$ & $\sqrt{ }$ \\
\hline & $\begin{array}{l}\text { Have discount rates been described and justified } \\
\text { given the target decision-maker? }\end{array}$ & NC & NA & $\sqrt{ }$ \\
\hline \multirow[t]{3}{*}{ D2d } & Are the utilities incorporated into the model appropriate? & NA & NA & $\sqrt{ }$ \\
\hline & Is the source for the utility weights referenced? & NA & NA & $x$ \\
\hline & Are the methods of derivation for the utility weights justified? & NA & NA & $x$ \\
\hline \multirow[t]{5}{*}{ D3 } & $\begin{array}{l}\text { Have all data incorporated into the model been described } \\
\text { and referenced in sufficient detail? }\end{array}$ & NC & $\sqrt{ }$ & $\sqrt{ }$ \\
\hline & $\begin{array}{l}\text { Has the use of mutually inconsistent data been justified } \\
\text { (i.e. are assumptions and choices appropriate)? }\end{array}$ & NC & NC & $\sqrt{ }$ \\
\hline & Is the process of data incorporation transparent? & $\sqrt{ }$ & $x$ & $x$ \\
\hline & $\begin{array}{l}\text { If data have been incorporated as distributions, } \\
\text { has the choice of distribution for each parameter } \\
\text { been described and justified? }\end{array}$ & NA & NA & NA \\
\hline & $\begin{array}{l}\text { If data have been incorporated as distributions, } \\
\text { is it clear that second order uncertainty is reflected? }\end{array}$ & NA & NA & NA \\
\hline \multirow[t]{2}{*}{ D4 } & Have the four principal types of uncertainty been addressed? & $x$ & $x$ & $x$ \\
\hline & $\begin{array}{l}\text { If not, has the omission of particular forms of } \\
\text { uncertainty been justified? }\end{array}$ & $x$ & $x$ & $x$ \\
\hline D4a & $\begin{array}{l}\text { Have methodological uncertainties been addressed by } \\
\text { running alternative versions of the model with different } \\
\text { methodological assumptions? }\end{array}$ & $x$ & $x$ & $x$ \\
\hline D4b & $\begin{array}{l}\text { Is there evidence that structural uncertainties have been } \\
\text { addressed via sensitivity analysis? }\end{array}$ & $x$ & $x$ & $x$ \\
\hline D4c & $\begin{array}{l}\text { Has heterogeneity been dealt with by running the } \\
\text { model separately for different subgroups? }\end{array}$ & $x$ & $x$ & $x$ \\
\hline \multirow[t]{2}{*}{ D4d } & $\begin{array}{l}\text { Are the methods of assessment of parameter } \\
\text { uncertainty appropriate? }\end{array}$ & $\sqrt{ }$ & $\sqrt{ }$ & $\sqrt{ }$ \\
\hline & $\begin{array}{l}\text { If data are incorporated as point estimates, are the ranges } \\
\text { used for sensitivity analysis stated clearly and justified? }\end{array}$ & NC & $\sqrt{ }$ & $\sqrt{ }$ \\
\hline C1 & $\begin{array}{l}\text { Is there evidence that the mathematical logic of the } \\
\text { model has been tested thoroughly before use? }\end{array}$ & $x$ & $x$ & $x$ \\
\hline \multirow[t]{3}{*}{$\mathrm{C} 2$} & Are any counterintuitive results from the model explained and justified? & NA & NA & NA \\
\hline & $\begin{array}{l}\text { If the model has been calibrated against independent data, have any differences been } \\
\text { explained and justified? }\end{array}$ & NA & NA & NA \\
\hline & $\begin{array}{l}\text { Have the results of the model been compared with those of previous models and any } \\
\text { differences in results explained? }\end{array}$ & $x$ & $x$ & $x$ \\
\hline \multicolumn{2}{|c|}{ Score, ratio ${ }^{\mathrm{TM}}(\%)$} & $21 / 38(55 \%)$ & 24/38 (63\%) & 28/43 (65\%) \\
\hline
\end{tabular}

NA Not Applicable, NC Not Clear

aAvailable from [20]: Philips Z, Ginnelly L, Sculpher M, Claxton K, Golder S, Riemsma R, Woolacott N and Glanville J. Review of guidelines for good practice in decision-analytic modelling in health technology assessment. Health Technol Assess 2004;8(36)

${ }^{\mathrm{T}}$ Ratio $=\mathrm{b} / \mathrm{a}$, where $\mathrm{b}=$ sum of tick; $\mathrm{a}=$ sum of items (excluding 'NA' items) 
all the studies included in the review, but only one of these studies [11] met all reporting and quality criteria. Differences in study design make it difficult to draw definitive conclusions as to whether the use of EUS as an additional staging technique could be considered cost-effective i.e. value for money which can be assessed by comparing the costs (monetary term) and health effects (non-monetary term) of an intervention with the alternative. Health effect of an intervention is usually measured in terms of QALYs (QualityAdjusted Life Years), a summary measure of health outcome and also a common unit used for economic evaluation of an intervention, as recommended by the UK's NICE (The National Institute for Health and Care Excellence) [28]. Given the differences in study design, a head-to-head comparison of the results couldn't be made from the Russell et al. (2013) [11] and Wallace et al. (2002) [31] studies to draw definitive conclusions. Although both of these studies had evaluated both costs and QALYs, their respective study designs were too different to allow direct comparison; one was an economic evaluation study using primary data [11] and the other an economic modelling study using secondary data [31]. Nevertheless, the economic evidence identified in this review, especially the better quality studies, provided useful findings on the value of EUS staging in the management of GOC patients, which could be of importance to policymakers and healthcare commissioners.

Among the six studies included in the review, two studies $[11,31]$ are the most robust in terms of including and comparing the relative costs and QALYs of different staging strategies, for example GOC staging with and without EUS. Findings from both of these two studies demonstrated that use of EUS as an additional imaging technique could save costs and offer greater QALY gains. This could be due to the fact that EUS has been known to be beneficial in terms of its sensitivity for locoregional staging of GOC [4, 6, 8, 32-34]. For that reason, using EUS as a complementary imaging technique to other imaging techniques such as CT and PET scanning for staging GOC could undoubtedly help minimise unnecessary treatments $[4,35,36]$; and thus potentially could save costs and offer greater health benefits to patients in terms of QALY gains. The EUS cost saving evidence was also supported by the remaining four studies [26, 27, 29, 30] evaluating only the cost of EUS e.g. whether EUS is a cost saving strategy or the least costly staging strategy. Russell et al. (2013) [11] further argued that EUS has a considerably high probability of being cost-effective under current recommended UK NICE's threshold of $£ 20,000$ to $£ 30$, 000 per QALY [28]. Thus, despite the scarcity of economic evidence in this field, from these studies identified in the review, there is some positive economic evidence relating to the cost-effectiveness of EUS in the management of patients with GOC.

\section{Strength and limitations of review methods}

This review adds to the literature by providing critical evaluation of the health economics evidence of EUS staging in gastro-oesophageal cancers (GOCs), for which there is a lack of well-conducted economic studies. Though a systematic review in this field was published 20 years ago [37], this systematic review is the most upto-date collection of economic literature in this area. Twenty years on since the review by Harris et al. (1998) [37], still only six papers were found in the area of health economics of EUS staging in GOC. This shows that there is a lack of prioritisation of research in this area.

Broad search terms were used to develop a comprehensive search strategy for each of the databases used in this systematic review. The resultant retrieved studies were quality appraised, using both the published standard checklists recommended for use in assessing the quality of economics articles in systematic review - the Critical Appraisal Skills Programme (CASP) economic evaluation checklist [19] and the Philips et al's economic modelling checklist [20] for the retrieved economic studies and economic modelling studies, respectively. The narrative summary of the review not only described the economic evidence of EUS staging in GOC but also served as a platform for providing a holistic insight into the health economics research available to date in this area. The latter is particularly helpful for commissioners, clinicians and researchers to elicit information and potentially to facilitate the development of further research in this area.

This review has several limitations. Heterogeneity of the included studies in the review in terms of study designs and methods meant that a meta-analysis of studies was not possible and a narrative summary was used. We also acknowledge that different countries have different thresholds for both the investigation of, and surgical management of gastro-oesophageal malignancies. This can result in variation between practices and hence difficulty in translating financial recommendations across regions. In terms of impact that EUS has on patients' quality of life and its costs, the lack of the availability of health economics research in this area means that it is considerably difficult, particularly for commissioners and clinicians, to guide evidence-based practice from an economic perspective.

\section{Further research}

This systematic review shows that the economic evidence available to date in this area is still scarce. There was a lack of health economic research collecting data, especially primary data, on both costs and effects (such as utility values to construct QALYs) of EUS staging in GOC. To improve this, there is a need for more primary health economic research in this 
area, particularly integrated clinical and economic trials of EUS staging in GOC that can offer robust evidence of costs and effects.

\section{Conclusions}

Despite the lack of economic evidence on costs and benefits of EUS staging for GOC, the data available from this review suggest use of EUS as a complementary staging technique to other staging techniques for GOC appears to be cost saving and offers greater QALYs. Based on the only randomised controlled trial conducted in the UK identified in this review, EUS seems to have high probability of being cost-effective at the UK NICE's threshold of $£ 20,000-£ 30,000$ per QALY. Nevertheless, future studies are necessary because the economic evidence around EUS staging interventions for GOC is far from robust. More health economic research and good quality data are needed to judge the economic benefits of EUS staging for GOC, particularly primary health economic research that collects primary data on the costs and effects (such as QALYs) of EUS staging in GOC.

\section{Additional file}

Additional file 1: An example of search strategy used in the Medline Ovid database. Medline ovid search strategy for the systematic review (DOCX $18 \mathrm{~kb})$

\section{Abbreviations}

CASP: Critical Appraisal Skills Programme; CRUK: Cancer Research United Kingdom; CT: Computer tomography; EUS: Endoscopic ultrasound; GOCs: Gastro-oesophageal cancers; MRI: Magnetic resonance imaging; PET: Positron emission tomography; RCT: Randomised controlled trials

\section{Acknowledgements}

The authors would like to thank the information specialist, Yasmin Noorani, at Bangor University, for her initial guidance in developing the search strategies.

\section{Authors' contributions}

STY was the chief investigator and the primary reviewer of this systematic review study, developed and designed the search strategy for each of the databases used in this review, undertook the review work with oversight from NB and with advice from RTE, $\mathrm{HH}$ and $\mathrm{ZH}$, and wrote the first draft of the systematic review paper. NB provided oversight for the systematic review work, contributed to the development of the search terms and the revision of the paper, and was the second reviewer. STY and NB were involved in the data extraction and in revising the manuscript critically for important intellectual content. $\mathrm{HH}$ contributed to the development of the search terms and the revision of the paper. ZH and RTE contributed to the revision of the paper. Each author has participated sufficiently in the work and takes responsibility for appropriate portions of the content. All authors have read and have given final approval of the version to be published.

\section{Funding}

This systematic review was undertaken as part of the PhD study, funded by the Tenovus Cancer Care Charity. The views expressed in this article are those of the authors and not those of the Tenovus Cancer Care Charity. The Tenovus Cancer Care Charity did not involve in the design of the study and collection, analysis, and interpretation of data and in writing the manuscript. Besides the PhD studentship awarded to the first author (STY) of this article by the Tenovus Cancer Care Charity, there is no other specific funding was received for this study.

\section{Availability of data and materials}

Available data was presented in the main manuscript. And, one additional file was generated.

Ethics approval and consent to participate Not applicable.

\section{Consent for publication \\ Not applicable.}

\section{Competing interests}

The authors declare that they have no competing interests.

\section{Author details}

${ }^{1}$ Centre for Health Economics and Medicines Evaluation (CHEME), Bangor University, Ardudwy, Normal Site, Holyhead Road, Bangor, Gwynedd LL57 2PZ, UK. ${ }^{2}$ Cancer Biomarkers Group, Swansea University, Singleton Park, Swansea SA2 8PP, UK. ${ }^{3}$ North Wales Organisation for Randomised Trials in Health and Social Care (NWORTH), Bangor University, Y Wern, Normal Site, Holyhead Road, Bangor, Gwynedd LL57 2PZ, UK.

Received: 3 September 2018 Accepted: 30 August 2019

Published online: 09 September 2019

\section{References}

1. Cancer Research UK (CRUK). Oesophageal Cancer Incidence Statistics. 2018. http://www.cancerresearchuk.org/health-professional/cancer-statistics/ statistics-by-cancer-type/oesophageal-cancer.

2. Cancer Research UK (CRUK). Stomach Cancer Incidence Statistics. 2018. http://www.cancerresearchuk.org/health-professional/cancer-statistics/ statistics-by-cancer-type/stomach-cancer.

3. Dubecz A, Solymosi N, Stadlhuber RJ, Schweigert M, Stein HJ, Peters JH. Does the incidence of adenocarcinoma of the esophagus and gastric cardia continue to rise in the twenty-first century? ASEER database analysis. J Gastrointest Surg. 2013;18:2345-8.

4. Allum WH, Griffin SM, Watson A, Colin-Jones D, on behalf of the Association of Upper Gastrointestinal Surgeons of Great Britain and Ireland, the British Society of Gastroenterology, and the British Association of Surgical Oncology. Guidelines for the management of oesophageal and gastric cancer. Gut. 2002;50(Suppl V):v1-v23.

5. Vilgrain V, Mompoint D, Palazzo L, et al. Staging of esophageal carcinoma: comparison of results with endoscopic sonography and CT. Am J Roentgenol. 1990;155:277-81.

6. Botet JF, Lightdale CJ, Zauber AG, et al. Preoperative staging of esophageal cancer: comparison of endoscopic US and dynamic CT. Radiology. 1991a; 181:419-25.

7. Lowe VJ, Booya F, Fletcher JG, Nathan M, Jensen E, Mullan B, et al. Comparison of positron emission tomography, computed tomography, and endoscopic ultrasound in the initial staging of patients with esophageal cancer. Molecular imaging and biology: MIB: the official publication of the Academy of Molecular Imaging. 2005;7(6):422-30.

8. van Vliet EP, Heijenbrok-Kal MH, Hunink MG, Kuipers EJ, Siersema PD. Staging investigations for oesophageal cancer: a meta-analysis. Br J Cancer. 2008;98(3):547-57.

9. Allum WH, Blazeby JM, Griffin SM, Cunningham D, Jankowski JA, Wong R, Association of Upper Gastrointestinal Surgeons of Great Britain and Ireland, the British Society of Gastroenterology and the British Association of Surgical Oncology. Guidelines for the management of oesophageal and gastric cancer. Gut. 2011;60(11):1449-72.

10. Healthcare Quality Improvement Partnership Ltd. (HQIP). National Oesophago-Gastric Cancer Audit 2016: An audit of the care received by people with Oesophago-Gastric Cancer in England and Wales 2016 Annual Report NHS Digital 2016. https://digital.nhs.uk/data-and-information/ publications/statistical/national-oesophago-gastric-cancer-audit/nationaloesophago-gastric-cancer-audit-2016-annual-report.

11. Russell IT, Edwards RT, Gliddon AE, Ingledew DK, Russell D, Whitaker R, Yeo ST, Attwood SE, Barr H, Nanthakumaran S, Park KGM. Cancer of Oesophagus or Gastricus - New Assessment of Technology of Endosonography (COGNATE): report of pragmatic randomised trial. Health Technol Assess. 2013;17:39. https://doi.org/10.3310/hta17390. 
12. University of York Centre for Reviews and Dissemination. Systematic Reviews: CRD's guidance for undertaking reviews in health care. York: Centre for Reviews and Dissemination, University of York; 2009.

13. Yeo ST, Bray N, Haboubi H, Hoare Z, Edwards RT. Economic evidence for EUS staging in patients with gastro-oesophageal cancer (GOC): protocol for a systematic review. PROSPERO 2016:CRD42016043700. 2016. http://www. crd.york.ac.uk/PROSPERO/display_record.php?ID=CRD42016043700.

14. Moher D, Liberati A, Tetzlaff J, Altman DG, The PRISMA Group. Preferred Reporting Items for Systematic Reviews and Meta-Analyses: The PRISMA Statement. PLoS Med. 2009;6(7):e1000097. https://doi.org/ 10.1371/journal.pmed1000097.

15. Liberati A, Altman DG, Tetzlaff J, Mulrow C, Gotzche PC, loannidis JPA, Clarke M, Devereaux PJ, Klwijnen J, Moher D. The PRISMA statement for reporting systematic reviews and meta-analyses of studies that evaluate health care interventions: explanation and elaboration. Ann Intern Med. 2009;6(7):1-28

16. Lang E. The well-built clinical question: a key to evidence-based decisions. McGill Journal of Medicine. 2004;8(1):90-3.

17. Schardt C, Adams MB, Owens T, Keitz S, Fontelo P. Utilization of the PICO framework to improve searching PubMed for clinical questions. BMC Medical Informatics and Decision Making. 2007;7:16 https://doi.org/10.1186/1472-6947-7-16.

18. Ronellenfitsch U, Schwarzbach M, Hofheinz R, Kienle P, Kieser M, Slanger TE, Jensen K, GE adenocarcinoma meta-analysis group. Perioperative chemo (radio) therapy versus primary surgery for resectable adenocarcinoma of the stomach, gastroesophageal junction, and lower esophagus. Cochrane Database Syst Rev. 2013;5:CD008107. https://doi.org/10.1002/14651858. CD008107.pub2.

19. Critical Appraisal Skills Programme (CASP). CASP Economic Evaluation Checklist. 2017. http://www.casp-uk.net/casp-tools-checklists.

20. Philips Z, Ginnelly L, Sculpher M, Claxton K, Golder S, Riemsma R, Woolacott N, Glanville J. Review of guidelines for good practice in decision-analytic modelling in health technology assessment. Health Technol Assess. 2004;8:36.

21. International Monetary Fund (IMF). Exchange Rate Archives by Month. 2017. http://www.imf.org/external/np/fin/data/param_rms_mth.aspx.

22. Curtis L, Netten A. Unit Costs of Health and Social Care 2005. Kent: Personal Social Services Research Unit (PSSRU), University of Kent; 2005.

23. Curtis L, Burns A. Unit Costs of Health and Social Care 2015. Kent: Personal Social Services Research Unit (PSSRU), University of Kent; 2015.

24. Curtis L, Burns A. Unit Costs of Health and Social Care 2016. Kent: Personal Social Services Research Unit (PSSRU), University of Kent; 2016.

25. Curtis L, Burns A. Unit Costs of Health and Social Care 2017. Kent: Personal Social Services Research Unit (PSSRU), University of Kent; 2017.

26. Shumaker DA, de Garmo P, Faigel DO. Potential impact of preoperative EUS on esophageal cancer management and cost. Gastrointest Endosc. 2002; 56(3):391-6. https://doi.org/10.1067/mge.2002.126831.

27. Chang KJ, Soetikno RM, Bastas D, Tu C, Nguyen PT. Impact of endoscopic ultrasound combined with fine-needle aspiration biopsy in the Management of Esophageal Cancer. Endoscopy. 2003;35(11):962-5.

28. National Institute for Health and Care Excellence (NICE). Guide to the methods of technology appraisal 2013. 2018. https://www.nice.org.uk/ process/pmg9/resources/guide-to-the-methods-of-technology-appraisal-2 013-pdf-2007975843781.

29. Hadzijahic N, Wallace MB, Hawes RH, VanVelse A, LeVeen M, Marsi V, Hoffman BJ, Sahai AV. CT or EUS for the initial staging of esophageal cancer? A cost minimization analysis. Gastrointest Endosc. 2000;52(6):715-20. https://doi.org/ 10.1067/mge.2000.108481

30. Harewood GC, Wiersema MJ. A cost analysis of endoscopic ultrasound in the evaluation of esophageal cancer. Am J Gastroenterol. 2002;97(2):452-8.

31. Wallace MB, Nietert PJ, Earle C, Krasna MJ, Hawes RH, Hoffman BJ, Reed CE. An analysis of multiple staging management strategies for carcinoma of the esophagus: computed tomography, endoscopic ultrasound, positron emission tomography, and thoracoscopy/laparoscopy. Ann Thorac Surg. 2002;74:1026-32.

32. Botet JF, Lightdale CJ, Zauber AG, et al. Preoperative staging of gastric cancer: comparison of endoscopic US and dynamic CT. Radiology. 1991b;181:426.

33. Grimm H, Binmoeller KF, Hamper $K$, et al. Endosonography for preoperative locoregional staging of esophageal and gastric cancer. Endoscopy. 1993;25:224.

34. Takizawa K, Matsuda T, Kozu T, et al. Lymph node staging in esophageal squamous cell carcinoma: a comparative study of endoscopic ultrasonography versus computed tomography. J Gastroenterol Hepatol. 2009;24:1687.

35. Rösch T, Lorenz R, Zenker $\mathrm{K}$, et al. Local staging and assessment of resectability in carcinoma of the esophagus, stomach, and duodenum by endoscopic ultrasonography. Gastrointest Endosc. 1992;38:460.

36. Dittler HJ. Assessment of resectability of gastrointestinal cancers by endoscopic ultrasonography. Gastrointest Endosc Clin N Am. 1995;5:569.

37. Harris KM, Kelly S, Berry E, Hutton J, Roderick P, Cullingworth J, et al. Systematic review of endoscopic ultrasound in gastro-oesophageal cancer. Health Technol Assess. 1998;2:18.

\section{Publisher's Note}

Springer Nature remains neutral with regard to jurisdictional claims in published maps and institutional affiliations.
Ready to submit your research? Choose BMC and benefit from:

- fast, convenient online submission

- thorough peer review by experienced researchers in your field

- rapid publication on acceptance

- support for research data, including large and complex data types

- gold Open Access which fosters wider collaboration and increased citations

- maximum visibility for your research: over $100 \mathrm{M}$ website views per year

At BMC, research is always in progress.

Learn more biomedcentral.com/submissions 